\title{
ATIVIDADES DE INVESTIGAÇÃO ESCOLAR: ANÁLISE PSICANALITICA DO ENGAJAMENTO EM PEQUENOS GRUPOS
}

\author{
JOSIMEIRE M. JÚLIO \\ Professora adjunta do Departamento de Metodologia de Ensino da \\ Universidade Federal de São Carlos \\ josimeire@ufscar.br
}

\begin{abstract}
ARNALDO M. VAZ
Professor adjunto em exercício do Colégio Técnico da Escola de Educação Básica e Profissional e professor do Programa de Pós Graduação: Conhecimento e Inclusão Social em Educação da Universidade Federal de Minas Gerais

arnaldovaz@ufmg.br
\end{abstract}

\begin{abstract}
RESUMO
Observamos grupos de alunos de ensino médio que foram desafiados a realizar uma atividade de pesquisa em Física. O objetivo era distinguir o engajamento colaborativo de outras formas de participação em grupo. Apresentamos um estudo pormenorizado de aulas que ocorreram no início do ano letivo em turmas do primeiro ano. Recorremos a gravações em áudio e vídeo para categorizar a participação dos alunos durante a atividade. As categorias são inspiradas no referencial psicanalítico de Grupos de Trabalho e Suposições Básicas. Com a ajuda desses conceitos foi possível caracterizar a participação individual no grupo, atentando para os impulsos emocionais que desviaram os indivíduos da tarefa. Baseados nos dados obtidos e em outros trabalhos nos quais analisamos esses grupos isoladamente, concluímos que a participação dos alunos depende de aspectos intrínsecos da dinâmica dos grupos de aprendizagem. A colaboração e objetividade, necessárias para que o grupo funcione bem, dependem de uma interferência externa ao grupo.

ALUNOS - PARTICIPAÇÃO DO ALUNO - APRENDIZAGEM - GRUPO DE TRABALHO
\end{abstract}

\section{ABSTRACT}

EDUCATIONAL INVESTIGATION ACTIVITIES: A PSYCHOANALYTICAL ANALYSIS OF ENGAGEMENT IN SMALL GROUPS. We observed groups of secondary school students who were challenged to conduct a research activity in physics. The objective was to distinguish

Artigo elaborado com base em comunicação oral apresentada no 6을 Encontro Nacional de Pesquisa em Educação em Ciências, realizado entre 26 de novembro a 2 de dezembro de 2007, Florianópolis (SC). 
collaborative engagement from other forms of group participation. We present a detailed study of lessons that occurred at the beginning of the school year in first year student classes. We used audio and video recordings to categorize the students' participation during the activity. The categories draw their inspiration from the psychoanalytical approach of Working Groups and Basic Assumptions. With the help of these concepts, it was possible to characterize individual participation in the group, paying attention to the emotional impulses that diverted individuals from the task in hand. Based on the data obtained and on other works in which we analyzed these groups in isolation, we conclude that student participation depends on intrinsic aspects of the dynamics of the learning groups. Collaboration and objectivity, which are necessary for the group to function well, depend on interference that comes from outside the group. STUDENTS - STUDENTS PARTICIPATION - LEARNING - WORK GROUP

Segundo Millar ( 199 |), habilidades cognitivas gerais como a observação, investigação e categorização são inatas nos seres humanos, por isso é impróprio dizer que são ensináveis. Adey (1997), por sua vez, considera que as funções gerais ensináveis existem, mas são difíceis de caracterizar com rigor. Concordamos que existam habilidades cognitivas tanto inatas quanto ensináveis, por isso buscamos identificar iniciativas que permitam o desenvolvimento de ambas as categorias. Relatamos aqui um estudo em que atentamos para a influência das escolhas do professor e da adoção de atividades de investigação sobre as habilidades cognitivas dos alunos.

Investigamos a influência das escolhas do professor pois levamos em conta o princípio da dialogicidade (Shor, Freire, 1987; Vaz, 1996). A adoção de atividades de investigação tem sido estudada em trabalhos empreendidos em nosso grupo de pesquisa sobre a qualidade do pensamento dos alunos nas atividades de laboratório e sobre a articulação dos alunos em grupos de aprendizagem (Borges,Vaz, Borges, 200 I ; Borges, Gomes, 2005; Júlio, Vaz, 2004, 2005; Júlio, Vaz, Fagundes, 2006). Esses trabalhos estão inseridos em um programa de pesquisa centrado na análise e no desenvolvimento de currículos que estimulem o pensamento científico entre os estudantes (Júlio, Vaz, 2004; Borges, Borges, 200I).

As atividades de investigação escolar em Física que estudamos são práticas ou simulações em que o engajamento individual e a colaboração coletiva levam os alunos a encontrar meios de responder questões inicialmente abertas. $\bigcirc$ sucesso desse tipo de atividade depende de os alunos acreditarem que se irão beneficiar do trabalho colaborativo, a despeito das diferenças de habilidade, interesse e nível de conhecimento. Professores da área de ciências, 
há muito tempo, defendem o recurso a atividades colaborativas de resolução de problemas, conduzidas por alunos trabalhando em grupo. Os pesquisadores têm sido mais cuidadosos ao averiguar qual o intervalo de validade dessa afirmação (Barron, 2003; Coleman, 1998; Duschl, Osborne, 2002; Hogan, Nastasi, Pressley, 2000).

Paralelamente, alguns estudos têm contribuído para consolidar o potencial de teorias psicanalíticas na análise do trabalho em grupos de aprendizagem no ensino de Física (Barolli, Villani, 1998; Barros et al., 2007; Barros, Laburu, Rocha, 2007; Barros, Villani, 2004). Para que pudessem se dar conta do que ocorre em atividades didáticas de laboratório, Barolli e Villani (1998) adaptaram a teoria psicanalítica de Bion ( 196 I) para dinâmica de grupos de laboratório. Outros trabalhos valeram-se desse referencial para aumentar o entendimento do trabalho em grupos de aprendizagem no ensino de Física (Barolli, Villani, 1998; Barros, Laburu, Rocha, 2007; Barros, Villani, 2004). Nós temos interesse em analisar o envolvimento dos alunos em atividades de investigação, enfrentando dessa maneira as dificuldades de avaliá-las. Assim, recorremos a esses parâmetros com o propósito de aprimorar a percepção do envolvimento dos alunos em grupos de aprendizagem. $\bigcirc$ objetivo é diferenciar o envolvimento colaborativo dos alunos de outras formas de participação no trabalho dos grupos.

Adotamos o referencial psicanalítico de Bion ( 1961 ) adaptado por Barolli e Villani ( 1 998) em formato ligeiramente alterado. Temos sido bem-sucedidos em utilizar esse referencial para analisar uma situação de sala de aula que vimos investigando de diferentes perspectivas; os resultados obtidos são complementares entre si (Júlio, Vaz, 2004, 2005; Júlio, Vaz, Fagundes, 2006). Apresentamos a metodologia de análise utilizada e uma descrição analítica pormenorizada da situação de aprendizagem. Discutimos os resultados tomando por base os conceitos de Grupos de Trabalho e Suposições Básicas. Concluímos identificando as condições nas quais os pequenos grupos se engajaram em trabalho colaborativo e retornaram às tarefas de aprendizagem.

\section{GRUPOS DE TRABALHO E GRUPOS DE SUPOSIÇÕES BÁSICAS}

Do ponto de vista de Bion ( 196 I), a dinâmica de todo grupo é conduzida ao mesmo tempo em dois níveis mentais distintos. Num deles, consciente, o 
trabalho é cooperativo e se orienta em torno da tarefa a ser realizada; a esse nível denominamos Grupo de Trabalho. O outro nível, inconsciente, é guiado por impulsos emocionais que levam os indivíduos a conduzir suas atividades não em torno da tarefa, mas de acordo com suposições básicas comuns a todo o grupo. Bion identifica três tipos de suposições básicas. Na primeira delas - suposição básica de dependência - o grupo precisa de um líder que o sustente. Na segunda - suposição básica de acasalamento - o grupo alimenta a esperança de que uma pessoa ou ideia o salvará de suas frustrações. $\mathrm{Na}$ terceira - suposição básica luta/fuga - o grupo se reúne para lutar ou fugir de alguma coisa ou inimigo que supostamente prejudica seu trabalho. Esses níveis inconscientes de operação têm a função de aliviar tensões que surgem no grupo durante a execução da tarefa. Entretanto, o trabalho colaborativo em torno da tarefa é comprometido quando a dinâmica do grupo se articula predominantemente em torno de suposições básicas.

Bion desenvolveu seus conceitos estudando grupos submetidos à terapia psicanalítica. Barolli e Villani (1998) trouxeram esses conceitos para a análise de grupos de aprendizagem no laboratório escolar, fazendo um paralelo com grupos terapêuticos. Analisaram grupos de aprendizagem em um curso de Física de nível universitário. Para esta investigação, adotamos esses conceitos em um formato ligeiramente alterado. Estamos interessados nas interações de sala de aula. Embora haja semelhanças com o trabalho de Barolli e Villani ( 1998), as diferenças exigem adaptações. Por exemplo, redefinimos Grupo de Trabalho como grupo de alunos que trabalham de maneira colaborativa entre si, permanecendo atentos predominantemente à tarefa de aprendizagem. Definimos como tarefas de aprendizagem aquelas que permitem o avanço do grupo do ponto de vista da atividade. Barros, Laburu e Rocha (2007) exemplificam como a ação do professor pode intervir nas relações de liderança e de aprendizagem estabelecidas em um grupo. Consideramos que as tarefas de aprendizagem estão em consonância com a direção apontada pelo professor durante a condução da atividade pelos grupos.

Redefinimos Grupos de Trabalho como os grupos de aprendizagem em que os alunos atuam colaborativamente entre si, mantendo-se centrados predominantemente na realização de uma tarefa de aprendizagem ou problema que cabe ao grupo solucionar. Nessa situação, o trabalho dos grupos é liderado pela tarefa de aprendizagem. Os grupos serão guiados por suposições básicas todas 
as vezes que deixarem de atuar colaborativamente ou fugirem aos propósitos da tarefa de aprendizagem e/ou da solução do problema. Nesse caso, serão guiados por tarefas de suposição básica. Em suma, recorremos aos conceitos psicanalíticos estabelecidos por Bion ( 1961 ) para analisar grupos de alunos no âmbito do ensino de Física de nível médio, em atividades de investigação que requerem o engajamento pessoal e a colaboração coletiva. Dispusemo-nos a entender o que, nesse contexto, distingue um Grupo de Trabalho de outro tipo de participação em um trabalho de grupo.

\section{METODOLOGIA}

Apresentamos os resultados de uma metodologia de análise dos dados aprimorada em trabalhos anteriores (Júlio, Vaz, 2004; 2005; Júlio, Vaz, Fagundes, 2006), nos quais analisamos grupos de alunos durante a realização de uma atividade de investigação guiada pelo professor. A base para coleta de dados é uma sequência de quatro aulas de Física de 50 minutos, divididas em duas seções de 100 minutos cada. A atividade de investigação foi conduzida por um dos autores deste texto nas duas turmas sob sua responsabilidade no início do ano letivo. Eram as primeiras aulas de Física das turmas, afora uma aula de apresentação. Elas ocorreram em uma escola com tradição de ensino prático, centrado no aluno.

A coleta de dados foi realizada mediante registros de vídeo e áudio. Ao chegarem em sala, os alunos encontraram a sala organizada em conjuntos de três carteiras e se reuniram em grupos de maneira aleatória. Havia uma câmera filmadora posicionada na frente da sala, que permitia fossem filmados seis grupos. Colocamos gravadores de áudio nos três grupos mais bem posicionados em relação à câmera. Um estudante de iniciação científica auxiliou na gravação das aulas, na identificação dos grupos e em parte da análise. A atividade submetida à análise denomina-se "Atividade das estrelas variáveis" ', e possui caráter introdutório, integrando o programa da primeira série da escola. O professor tenta levar os alunos a simularem o trabalho de uma comunidade

I. Elaborada pelo professor Norberto Cardoso Ferreira, da Universidade de São Paulo (www. ludoteca.if.usp.br). 
científica: investigar um fenômeno, procurar fazer descobertas, comunicá-las com objetividade e discuti-las com outros colegas.

Um envelope contendo 18 slides de uma mesma região do céu é entregue a trios ou quartetos de alunos; em cada slide há uma legenda que registra a região fotografada e a data da fotografia. Os alunos devem observar os slides, que foram previamente embaralhados, e descobrir se há algum fenômeno que valha a pena ser estudado. O professor propõe que participem de um jogo que simulará o trabalho de uma comunidade científica. São estabelecidas cinco regras básicas:

- Todas as descobertas devem ser apresentadas com base em evidências que serão submetidas à avaliação da comunidade.

- Todos devem discutir e estabelecer parâmetros comuns que serão adotados à medida que forem determinados.

- Os grupos trabalharão em suas investigações, mas em intervalos de tempo regulares haverá plenárias para que as descobertas sejam socializadas e discutidas pela comunidade.

- O clima de competição entre os grupos deve ser bem administrado, pois a troca entre eles será necessária para que o trabalho avance.

- As decisões e descobertas anunciadas devem ser éticas e não podem contrariar os contratos estabelecidos inicialmente em favor de interesses particulares de determinados grupos ou pessoas.

Analisamos da mesma forma as quatro aulas, contudo comunicamos apenas a análise das duas primeiras, pois as consideramos determinantes para o desenvolvimento da atividade. A análise de dados envolveu as seguintes etapas: a. elaboração de três mapas de eventos, um para cada grupo gravado em áudio; b. transcrição de todos os trechos em que havia participação do professor, tanto nas plenárias, quanto nos grupos; c. transcrição de trechos em que os alunos atuavam de forma cooperativa entre si, mas fugiam da tarefa a ser realizada; $d$. descrição escrita da aula a partir das interações entre os membros do grupo do ponto de vista da atividade; e. análise cruzada da descrição e das diversas análises obtidas nas etapas anteriores para os momentos de interação entre os membros do grupo entre si, com o professor e com os outros grupos; f. análise dos resultados obtidos na etapa "e" a partir do referencial psicanalítico. 
O trabalho de análise se ancorou em quatro instâncias intercaladas que nos permitiam acompanhar as interações dos membros dos grupos no percurso da aula. São elas: a. as intervenções de cada membro durante as tomadas de decisão no grupo; b. os momentos em que os grupos recorriam ao professor; c. as evidências de engajamento dos membros dos grupos com a atividade; d. as evidências de superação dos desafios propostos pelo professor durante o desenvolvimento da atividade. Essas instâncias foram privilegiadas e aprimoradas ao longo da análise para que pudéssemos verificar a participação dos alunos tanto nos grupos quanto nas plenárias.

\section{RESULTADOS E DISCUSSÃO}

O professor apresenta a atividade, em plenária, para toda a turma. Ao final da apresentação, inicia-se o trabalho dos grupos, que dura cerca de 80 minutos alternando as discussões em grupo com plenárias em que todos são estimulados a participar. Dividimos a atividade em três tarefas de aprendizagem, propostas pelo professor durante três das quatro plenárias organizadas por ele. A primeira tarefa é identificar no conjunto de slides distribuídos aos grupos algum fenômeno que valha a pena estudar. Como veremos, o fenômeno eleito é a mudança de tamanho das estrelas. A segunda tarefa é observar com cuidado a mudança de tamanho das estrelas; os alunos devem estudar melhor o fenômeno que descobriram. A terceira tarefa é medir a variação de tamanho das estrelas para posteriormente descrever como cada estrela muda de tamanho.

Em níveis diferentes, os três grupos analisados (G1, G2 e G3) atuam de maneira colaborativa e se envolvem na atividade. Entretanto, nem sempre se conseguem manter de forma consciente na realização das tarefas de aprendizagem, propostas pelo professor no decorrer da atividade. Em razão disso, identificamos, em vários momentos, conflitos surgidos nos grupos por causa de divergências entre ideias e ações. Consideramos a superação dessas dificuldades um indício de liderança da tarefa de aprendizagem. Isto é, o grupo reorganiza sua forma de trabalhar, privilegiando a realização da tarefa de aprendizagem sem se desviar dela.

Recorremos a uma breve descrição das plenárias e aos quadros I, 2 e 3 para ilustrar o andamento das tarefas de aprendizagem em cada um dos grupos monitorados. Descrevemos cada uma das três tarefas de aprendiza- 
gem do ponto de vista das ações dos grupos e, em seguida, as discutimos segundo os conceitos psicanalíticos de Bion. Raramente fizemos, nos quadros, referência a um único integrante dos grupos, dada a grande integração entre eles. Nesses quadros, destacamos algumas das interações que nos permitiram recorrer aos conceitos psicanalíticos para trazer a lume o tipo de envolvimento dos grupos com a atividade, com as tarefas de aprendizagem e as características de sua participação. Também fizemos referência a outros três grupos não monitorados (G4, G5 e G6), que participaram ativamente das discussões em plenária.

\section{QUADRO I}

\section{AÇÕES DOS GRUPOS COM GRAVADOR APÓS APRESENTAÇÃO DA ATIVIDADE}

\begin{tabular}{|c|c|c|}
\hline $\mathrm{GI}(\mathrm{BO}, \mathrm{RA}, \mathrm{PA})$ & G2 (NA, MA, ML) & G3 (MR, TO, PE) \\
\hline $\begin{array}{l}\text { Organizam slides de } \\
\text { acordo com as datas que } \\
\text { constam na legenda. }\end{array}$ & $\begin{array}{l}\text { 1. Assim que a atividade se } \\
\text { inicia, meninas perguntam } \\
\text { ao professor o que devem } \\
\text { fazer. } \\
\text { O professor esclarece } \\
\text { que devem identificar se } \\
\text { há alguma coisa ocorrendo } \\
\text { naqueles slides. }\end{array}$ & $\begin{array}{l}\text { I. Organizam slides de acor- } \\
\text { do com a legenda. }\end{array}$ \\
\hline $\begin{array}{l}\text { 2. RA percebe que alguns } \\
\text { pontos mudam de } \\
\text { tamanho. }\end{array}$ & $\begin{array}{l}\text { 2.Deduzem que podem } \\
\text { ser fotos de moléculas de } \\
\text { água, mudança de fase ou } \\
\text { gotas de óleo em suspen- } \\
\text { são em um líquido. }\end{array}$ & $\begin{array}{l}\text { 2. Comparam o primeiro } \\
\text { slide com o último, e } \\
\text { percebem que as estrelas } \\
\text { giraram. }\end{array}$ \\
\hline $\begin{array}{l}\text { 3.BO pergunta ao professor } \\
\text { se devem falar de coisas } \\
\text { científicas ocorrendo } \\
\text { ali. O professor diz que } \\
\text { devem observar os mapas } \\
\text { e dar evidências do que } \\
\text { perceberem que está } \\
\text { acontecendo. O grupo } \\
\text { nota que na legenda há um } \\
\text { código que identifica uma } \\
\text { região do céu. Conferem } \\
\text { a informação com o } \\
\text { professor e ele diz que faz } \\
\text { parte da tarefa discutirem } \\
\text { sobre ela. }\end{array}$ & $\begin{array}{l}\text { 3. Chamam o professor e } \\
\text { falam de suas impressões. } \\
\text { O professor sugere que } \\
\text { mostrem evidências } \\
\text { de que o fenômeno } \\
\text { que identificaram está } \\
\text { realmente ocorrendo e } \\
\text { para isso podem utilizar } \\
\text { as folhas da maneira } \\
\text { mais conveniente para as } \\
\text { observações. }\end{array}$ & $\begin{array}{l}\text { 3. Comparam slides do } \\
\text { primeiro dia de cada mês } \\
\text { e percebem diferença em } \\
\text { alguns pontos. }\end{array}$ \\
\hline
\end{tabular}

(continua) 
(continuação)

\begin{tabular}{|c|c|c|}
\hline $\begin{array}{l}\text { 4.Decidem que aquela é uma } \\
\text { região do céu e que estão } \\
\text { observando a mudança de } \\
\text { tamanho de alguns corpos } \\
\text { celestes. }\end{array}$ & $\begin{array}{l}\text { 4.Percebem que há datas } \\
\text { na legenda dos slides e } \\
\text { começam a organizá-los. }\end{array}$ & $\begin{array}{l}\text { 4. Supõem que observam } \\
\text { astros e que alguns deles } \\
\text { se movimentam e outros } \\
\text { não. }\end{array}$ \\
\hline $\begin{array}{l}\text { 5. Observam os corpos } \\
\text { que mudam de tamanho } \\
\text { e tentam encontrar } \\
\text { uma explicação para o } \\
\text { fenômeno. RA sugere } \\
\text { que se concentrem em } \\
\text { observar o fenômeno } \\
\text { evitando explicações. }\end{array}$ & $\begin{array}{l}\text { 5. Começam a superpor } \\
\text { as folhas na tentativa de } \\
\text { identificar algo. }\end{array}$ & $\begin{array}{l}\text { 5.Percebem na legenda que } \\
\text { se trata de uma região do } \\
\text { céu. }\end{array}$ \\
\hline \multirow[t]{4}{*}{$\begin{array}{l}\text { 6. Tentam verificar de modo } \\
\text { mais preciso a mudança } \\
\text { de tamanho, mas ficam in- } \\
\text { comodados por não saber } \\
\text { explicar por quê. }\end{array}$} & & $\begin{array}{l}\text { 6. Tentam verificar se algum } \\
\text { astro se desloca enquanto } \\
\text { os outros permanecem } \\
\text { fixos. }\end{array}$ \\
\hline & & $\begin{array}{l}\text { 7. Buscam evidências de } \\
\text { algum tipo de movimento } \\
\text { e concluem que quem } \\
\text { se move é quem tirou as } \\
\text { fotos. }\end{array}$ \\
\hline & & $\begin{array}{l}\text { 8. Tomam uma estrela central } \\
\text { como referência, batizam-na } \\
\text { Mickey, começam a superpor } \\
\text { os slides e descobrem que } \\
\text { as outras estrelas não se } \\
\text { deslocam em relação a ela. }\end{array}$ \\
\hline & & $\begin{array}{l}\text { 9. Chegam à conclusão que } \\
\text { são estrelas porque elas } \\
\text { não mudam de posição } \\
\text { umas em relação às } \\
\text { outras. }\end{array}$ \\
\hline
\end{tabular}

\section{Primeiro desafio: identificar algum fenômeno que valha a pena estudar}

O professor apresenta a atividade afirmando que ela tem características comuns às características de uma atividade científica. Após entregar aos grupos envelopes com os slides misturados, solicita que os analisem à procura de algum fenômeno, de algo significativo naquela região do céu. $\bigcirc$ trabalho inicia-se 
com o desafio: "Nas folhas distribuídas é possível identificar algum fenômeno que valha a pena estudar?" Nos grupos que monitoramos, ocorreram as ações discutidas no quadro I.

O professor organiza a primeira discussão coletiva e pergunta: "Afinal de contas, esses dados que estão aí são sobre o quê? Moléculas, fungos numa placa de Petri, sujeira no fundo de uma tigela, região do céu?".

GI e G3 dizem que os slides analisados se referem a uma região do céu, baseando-se na informação contida na legenda. Quando indagados se a região muda, os dois grupos divergem e debatem suas ideias mediados pelo professor, que solicita evidências durante a defesa de ambos os pontos de vista. $\mathrm{TO}$, representante de G3, defende que o que muda é a posição do observador, pois o grupo percebeu que nenhum dos astros se movimenta em relação aos outros, as distâncias entre eles permanecem iguais. $\mathrm{BO}$ e RA, integrantes de GI, mostram que em todos os slides o código que identifica a região é sempre o mesmo, para eles não é o observador que muda, mas os astros que passam por aquela região. GI e G3 passam a protagonizar a discussão em plenária.

O professor interrompe a discussão e conduz a plenária de acordo com aspectos levantados pelos dois grupos que se referiam à observação, como anotações na legenda e distância entre os astros. Ele também aponta as diferentes interpretações dos dois grupos sobre a mesma observação, versa sobre a diferença entre observação e interpretação, sugerindo que, a partir de tudo o que foi discutido, melhorem a observação.

As ações representadas no quadro I possibilitaram verificar que, logo após a apresentação da atividade, o grupo GI apreendeu a maneira mais promissora de conduzir a tarefa de aprendizagem. Seus membros trabalhavam integrados e se envolveram no desafio de perceber algo relevante que ocorria no conjunto de slides. No período 3 de GI percebemos uma interação com o professor, que the permitiu conduzir bem aquela etapa da investigação. Ao ser consultado pelo grupo, o professor se referiu à tarefa de aprendizagem tal qual ela foi proposta durante a apresentação da atividade em plenária: identificar um fenômeno naquelas folhas baseando-se em evidências concretas. GI aceitou o desafio demonstrando sua capacidade de atuar como Grupo de Trabalho. Trabalharam colaborativamente em função da tarefa de aprendizagem - identificar o fenômeno a ser estudado -, compartilharam informações, tomaram 
decisões juntos e evitaram se desviar da tarefa, destacando como fenômeno importante a mudança de tamanho das estrelas.

O grupo G2 encontrou dificuldade de conduzir a tarefa de aprendizagem. O modo de abordar o professor nos períodos I e 3 sugere uma tendência de se pautar por uma suposição básica de dependência em relação a ele. Sendo assim, os alunos esperavam que o professor assumisse a liderança do grupo dizendo que fenômeno deveriam estudar. Ao enfrentarem a dificuldade de identificar o fenômeno, abordaram o professor sugerindo que ele deveria "sustentar" o grupo para que a tarefa fosse realizada. $\bigcirc$ professor recusou-se a liderar 0 grupo, entretanto, não o rejeitou, mas o desafiou. Ainda que discretamente, esse desafio foi aceito por G2, que também passou a assumir características de Grupo de Trabalho. Começou a procurar um modo que levasse à descoberta de um fenômeno relevante para a observação.

O grupo G3 atuou colaborativamente desde o início da tarefa de aprendizagem. Juntos, os alunos perceberam diferenças entre os slides, formularam hipóteses, discutiram suas impressões, buscaram evidências para suas afirmações. A integração dos componentes do grupo era tão intensa que não chegaram a consultar o professor em nenhum momento. Embora tenha atuado predominantemente como Grupo de Trabalho, concentrando-se na tarefa de aprendizagem - identificar um fenômeno para análise -, G3 sujeitou-se a uma suposição básica de acasalamento em alguns momentos. Isto é, desviou-se da tarefa de identificar o fenômeno, alimentando a esperança de encontrar uma explicação para ele, e se envolveu em uma tarefa de suposição básica. Nos períodos 7 e 9, é possível perceber que os alunos julgaram que além de identificar o fenômeno precisavam explicá-lo. Para eles, a explicação levaria a evidências da ocorrência do fenômeno. A curiosidade pela descoberta fazia que não se percebessem fugindo da tarefa de aprendizagem; guiavam-se pela esperança de explicar o fenômeno antes dos outros grupos.

\section{Segundo desafio: observar com cuidado a mudança de tamanho das estrelas}

O professor aponta as diferentes interpretações dos grupos GI e G2 sobre a mesma observação e versa sobre a diferença entre observação e interpretação. A seguir sugere que, a partir de tudo o que foi discutido em 
plenária, os grupos trabalhem para melhorar a observação da mudança de tamanho das estrelas. Por fim, recomenda que solicitem os materiais que julguem poder auxiliá-los a fazer observações melhores. GI, G2 e G3 se articulam da seguinte maneira:

QUADRO 2

AÇÕES DOS GRUPOS COM GRAVADOR APÓS PRIMEIRA DISCUSSÃO COLETIVA

\begin{tabular}{|c|c|c|}
\hline $\mathrm{GI}(\mathrm{BO}, \mathrm{RA}, \mathrm{PA})$ & G2 (NA, MA, AL) & G3 (MR, TO, PE) \\
\hline $\begin{array}{l}\text { 7.Verificam que há movimen- } \\
\text { to de estrelas. }\end{array}$ & $\begin{array}{l}\text { 6.Voltam a procurar algum } \\
\text { fenômeno nos slides, mas } \\
\text { ainda não sabem qual é } \\
\text { a tarefa. }\end{array}$ & $\begin{array}{l}\text { 10. Tomam Mickey como } \\
\text { referência para fazer suas } \\
\text { observações. }\end{array}$ \\
\hline $\begin{array}{l}\text { 8. Tentam identificar que tipo } \\
\text { de movimento ocorre } \\
\text { com estrelas. }\end{array}$ & $\begin{array}{l}\text { 7. Comparam slides com } \\
\text { datas bem diferentes e } \\
\text { percebem que estrelas } \\
\text { giram em relação à } \\
\text { margem do papel. }\end{array}$ & $\begin{array}{l}\text { I. Percebem que uma estre- } \\
\text { la cresceu. }\end{array}$ \\
\hline $\begin{array}{l}\text { 9. Percebem que uma estrela } \\
\text { aumenta de tamanho e } \\
\text { procuram uma explicação. }\end{array}$ & $\begin{array}{l}\text { 8. Percebem movimento } \\
\text { anti-horário do conjunto } \\
\text { de estrelas. }\end{array}$ & $\begin{array}{l}\text { 12. Encontram outra estrela } \\
\text { crescendo e tentam de- } \\
\text { terminar o período em } \\
\text { que ocorre a mudança. } \\
\text { Ao acompanharem o } \\
\text { crescimento, se impres- } \\
\text { sionam com a diferença } \\
\text { de tamanho das estrelas e } \\
\text { falam que pode ter ocor- } \\
\text { rido alguma reação com } \\
\text { a estrela. }\end{array}$ \\
\hline \multicolumn{3}{|l|}{$\begin{array}{l}\text { 10.Discutem como poderiam } \\
\text { perceber a estrela de di- } \\
\text { ferentes pontos da Terra. }\end{array}$} \\
\hline \multicolumn{3}{|l|}{$\begin{array}{l}\text { I I.Elegem o crescimento da } \\
\text { estrela como fenômeno } \\
\text { importante. }\end{array}$} \\
\hline $\begin{array}{l}\text { 12. Observam que a estrela } \\
\text { volta a diminuir e ficam } \\
\text { intrigados. }\end{array}$ & & \\
\hline
\end{tabular}

Dez minutos depois, o professor promove nova plenária para que os grupos comuniquem suas observações. G4, um dos grupos não monitorados, apresenta suas observações, relatando que verificaram a mudança de tamanho de uma estrela, descreve como supõem que as fotos foram tiradas e como 
observaram o movimento de translação que provocou a mudança. $\bigcirc$ professor sugere aos grupos que diferenciem na fala do colega o que se refere à descrição da observação, o que é interpretação e o que não se encaixa em nenhuma dessas categorias. GI identifica alguns aspectos do que diz respeito à observação da mudança de tamanho da estrela na apresentação de G4 e contrapõe com o que observou. Após um breve comentário sobre o assunto, o professor sugere que G5, outro grupo não monitorado, fale sobre o movimento de translação que afirma ter identificado. G5 enfatiza características de movimentos de translação que diz ter observado muito semelhantes às relatadas por G4. O professor pergunta se outros grupos perceberam o mesmo. G3 não concorda com a ideia de translação.

professor discorre sobre a dificuldade de se fazer uma observação desvinculada da interpretação do fenômeno. Ele resgata, do relato dos grupos, pontos que exemplificam momentos em que eles se referiam à observação, à interpretação e a situações que não se enquadravam nessas categorias. São destacados, na maneira de trabalhar dos diversos grupos, fatores que interferem positivamente e negativamente na observação. Os grupos acompanham as orientações atentamente. Ao contrário de G2, que ouve o professor em silêncio e sem manipular os slides, GI e G3 trocam olhares entre si e conferem as informações da legenda e a posição das estrelas.

A análise, tomando por base o que se exemplifica no quadro 2, revelou que, à medida que melhoravam a observação, os grupos GI e G3 começaram a perceber o fenômeno da mudança de tamanho das estrelas com mais detalhes. Isso fez que esses grupos passassem a estudar o fenômeno com mais cuidado, atentando para o que ocorria em torno daquelas estrelas. A tarefa de melhorar a observação era mais específica e trouxe novos desafios para os grupos.

A configuração de Grupos de Trabalho, com grande integração entre os participantes na tentativa de realizar a tarefa de aprendizagem, tornou-se mais acentuada. Entretanto, verificamos, nos períodos 9 e 10 de G I e no período 12 de G3, que a curiosidade pelo fenômeno levou os alunos a fugir da tarefa de aprendizagem. Um exemplo está na transcrição a seguir, extraída de um diálogo entre os integrantes de G3 durante o período 12.

TO: Então!? E sem falar também, escutando o que ela falou (se referindo à fala de RA em plenária), as mudanças mais radicais estão acontecendo em dias pró- 
ximos, então não tem como se deslocar assim se for movimento de rotação!

Todos: É.

MR: Então essa distância assim entre um..., assim, e o meio delas é sempre a mesma, só vai mudar o tamanho.

PE: E se observar também em dias próximos também o ponto de referência da observação não pode mudar muito, também.

TO: Que isso, cara?

PE: Aí, é dedução.

MR: Vamos supor, você está vendo esta distância aqui em uma semana, aí, onde é que você vai ver em uma semana aqui pra mudar? (apontando para a legenda) TO: Ah é!? Tem semanas aí?

MR: Aqui você está olhando as semanas, você não está vendo? Agora vamos supor, você nota uma mudança radical em duas semanas, uma está assim e a outra já está daqui para cá.

TO: É

MR: Na primeira semana já acontece isso.

PE: Mas pode ser o seguinte também, cara: se tiverem poucas estrelas aumentando e diminuindo de tamanho, também pode ser uma reação das próprias aí, pode ser também que ela está gerando uma supernova... que ela está explodindo...

Eles deixaram de observar a mudança de tamanho das estrelas, pois sentiram necessidade de explicar o que estava ocorrendo naquela região do céu. Então, passaram a atuar em torno de uma tarefa de suposição básica de acasalamento, tentavam explicar o fenômeno na esperança de que isso os levasse a uma observação de melhor qualidade. Os grupos estavam muito envolvidos com a atividade, mas deixavam de atuar conscientemente em torno da tarefa de aprendizagem e buscavam uma compreensão que não poderiam alcançar com as informações de que dispunham. A ansiedade em conhecer melhor o fenômeno os levava a fugas inconscientes da tarefa de aprendizagem proposta pelo professor. No fundo, eles se valeram da busca de uma explicação para aliviar a tensão. 


\section{Terceiro desafio: medir a variação de tamanho das estrelas}

O professor refina a tarefa de aprendizagem anterior. Ele determina que, para melhorar a observação das estrelas, se deve medir a mudança de tamanho delas. Como nem todas são estrelas variáveis, uma tarefa de aprendizagem precede a medida proposta: identificar as estrelas variáveis. $\bigcirc$ professor estabelece um prêmio como estratégia de manutenção dos grupos na tarefa. Os grupos que identificarem estrelas que mudam de tamanho poderão dar nome a elas.

QUADRO 3

AÇÕES DOS GRUPOS COM GRAVADOR APÓS SEGUNDA DISCUSSÃO COLETIVA

\begin{tabular}{|c|c|c|}
\hline $\mathrm{GI}(\mathrm{BO}, \mathrm{RA}, \mathrm{PA})$ & G2 (NA, MA, ML) & G3 (MR, TO, PE) \\
\hline $\begin{array}{l}\text { 13. Percebem que outras es- } \\
\text { trelas mudam de tamanho. }\end{array}$ & 9.Leem a legenda. & $\begin{array}{l}\text { 13. Marcam duas estrelas que } \\
\text { mudam de tamanho. }\end{array}$ \\
\hline $\begin{array}{l}\text { 14. Chamam o professor e co- } \\
\text { municam o fato. O profes- } \\
\text { sor sugere que se concen- } \\
\text { trem numa boa descrição } \\
\text { de uma das estrelas. }\end{array}$ & $\begin{array}{l}\text { 0. Entendem que estão estu- } \\
\text { dando estrelas. }\end{array}$ & $\begin{array}{l}\text { 44.Procuram estrela que muda } \\
\text { mais rapidamente. }\end{array}$ \\
\hline $\begin{array}{l}\text { 5. Entendem, pela fala do } \\
\text { professor, que devem fazer } \\
\text { uma tabela. }\end{array}$ & $\begin{array}{l}\text { I।.Percebem a mudança de } \\
\text { tamanho de uma estrela, } \\
\text { começam a medi-la. }\end{array}$ & $\begin{array}{l}\text { I5. Formulam hipótese para } \\
\text { investigar movimento de } \\
\text { translação. }\end{array}$ \\
\hline $\begin{array}{l}\text { 16. Discutem com o professor } \\
\text { uma forma de melhorar a } \\
\text { medida. }\end{array}$ & $\begin{array}{l}\text { 12. Comparam estrelas para } \\
\text { ver se outras mudam de } \\
\text { tamanho. }\end{array}$ & $\begin{array}{l}\text { 16. Investigam se estrelas só } \\
\text { diminuem ou se só au- } \\
\text { mentam. Percebem duas } \\
\text { estrelas que só aumentam. } \\
\text { Discutem se estrelas po- } \\
\text { dem diminuir. }\end{array}$ \\
\hline \multirow[t]{2}{*}{$\begin{array}{l}\text { 17. Sugerem modificações no } \\
\text { instrumento que utilizam e } \\
\text { o professor traz uma escala } \\
\text { transparente. }\end{array}$} & & $\begin{array}{l}\text { 17. Comparam estrelas que } \\
\text { mudam de tamanho. }\end{array}$ \\
\hline & & $\begin{array}{l}\text { 18. Decidem observar a mu- } \\
\text { dança de tamanho de uma } \\
\text { estrela por vez. Começam } \\
\text { a fazer quadro para uma } \\
\text { das estrelas. }\end{array}$ \\
\hline
\end{tabular}

Logo após conversar sobre medidas com o grupo GI, o professor faz um anúncio para todos os grupos, eles poderiam utilizar réguas transparentes 
para realizar as medidas. Assim que entrega a todos as escalas transparentes, o professor atende ao chamado de G6, um grupo não monitorado, que solicita um sistema de coordenadas. Juntamente com esse grupo o professor estabelece que uma constelação central, parecida com a denominada na pesquisa, Mickey Mouse, seja adotada como origem de um sistema de referência cartesiano. Em seguida, entrega aos grupos uma grade quadriculada em acetato transparente. A partir desse momento, os grupos passam a realizar a tarefa de aprendizagem de maneira mais uniforme, procuram identificar, localizar e medir as estrelas. Para encerrar essa etapa da atividade, o professor faz, em plenária, uma síntese das tarefas de aprendizagem realizadas, anuncia a continuidade do trabalho na próxima aula e evidencia que vai comparar o modo como os grupos organizaram os dados que colheram.

Nessa fase da investigação, o trabalho dos grupos fica mais uniforme. A configuração de Grupos de Trabalho tornou-se predominante, além de trabalharem mais integrados, alguns componentes dos grupos já percebiam quando o grupo se desviava da tarefa de aprendizagem. Quando alguém do grupo tendia a levá-lo a pautar-se por uma tarefa de suposição básica, outro membro o fazia retornar ao trabalho em torno da tarefa de aprendizagem. Os grupos passaram a recorrer ao professor para comunicar suas descobertas ou solicitar recursos que lhes permitissem aprimorar a execução da tarefa de aprendizagem; nesses momentos, recebiam pistas para o refinamento dos métodos utilizados na investigação.

Um exemplo é o que observamos com GI no quadro 3, períodos I4, I 5 e 16. $\bigcirc$ professor atuou como fonte de referência que auxiliou o grupo a desenvolver técnicas e instrumentos que melhoravam a qualidade das observações e o pôs na frente em relação aos colegas. Imediatamente após conversar com Gl, o professor repassou a informação a todos os grupos em plenária. Isso deixava o trabalho de todos os grupos em condições de igualdade. Logo em seguida, ocorreu um episódio de mesma natureza envolvendo G6. O grupo solicitou uma maneira de determinar a localização das estrelas e, após tê-lo atendido, o professor compartilhou a informação com os demais grupos.

Ainda que atrasado na investigação, G2 passou a atuar mais predominantemente como Grupo de Trabalho. As sessões em plenária auxiliaram as integrantes de $\mathrm{G} 2$ a determinar o que observariam pelo modo pelo qual os 
outros grupos haviam percebido o fenômeno. Isso permitiu que elas organizassem melhor o trabalho.

\section{GRUPO DE TRABALHO E OUTRAS MODALIDADES DE PARTICIPAÇÃO EM TRABALHO EM GRUPO: DIFERENÇAS}

O acompanhamento detalhado dos grupos GI, G2 e G3 indicou que eles desempenharam suas funções cooperando uns com os outros, respeitando as opiniões e características individuais de cada um. $O$ conflito que apareceu de forma recorrente não só nesses, mas em todos os grupos da classe foi a dificuldade que os alunos encontraram de dissociar a observação da interpretação do fenômeno. Essa é uma tarefa de aprendizagem extremamente difícil de se concretizar em poucas aulas, sobretudo para alunos que acabaram de ingressar no ensino médio.

Consideramos o envolvimento dos alunos nessa atividade trabalho por um longo tempo como algo excepcional; não é comum, mas eles se mantiveram atentos e ativos, mesmo nas atividades de laboratório. Graças a esse comportamento, pudemos voltar a atenção para a qualidade do envolvimento dos alunos, procurando diferenciar a participação de um Grupo de Trabalho de outros tipos de participação. Ao longo da análise, os grupos de alunos se mostraram profundamente envolvidos com uma atividade de investigação. Entretanto, verificamos que interação com a atividade e cooperação entre elementos de um grupo não é garantia de engajamento nas tarefas de aprendizagem propostas pelo professor. Ficou evidente que fugir da tarefa de aprendizagem não implica necessariamente fugir do trabalho cooperativo.

Impulsos emocionais como ansiedade por uma nova descoberta ou angústia diante da dificuldade de observar ou descrever o fenômeno sem explicá-lo levaram os estudantes a se desviarem das tarefas de aprendizagem. Em vários momentos a observação e a descrição do fenômeno se constituíram no maior desafio para os alunos. Há que considerar que isso é parte do processo de amadurecimento do grupo. A busca por explicações surge naturalmente durante as observações e é reforçada nas tentativas de se fazerem descrições. Na situação de aprendizagem analisada, uma tarefa de suposição básica de acasalamento é recorrente no processo de desenvolvimento e refinamento das habilidades de observar e descrever o fenômeno. A tarefa de suposição 
básica de acasalamento caracteriza-se quando os estudantes buscam entender antes de descrever o fenômeno. Consideramos que eles foram guiados inconscientemente pela esperança de que assim agindo conseguissem observar melhor ou encontrar uma boa descrição para o fenômeno. Porém, quando bem administradas, essas fugas inconscientes cumpriram a função de aliviar as tensões do grupo em torno da dificuldade de realizar as tarefas de aprendizagem.

Verificamos que os alunos queriam fazer uma descoberta importante. Para eles essa descoberta só teria valor se viesse acompanhada de uma boa interpretação. Eles seguiam e confrontavam os passos indicados pelos colegas e pelo professor na esperança de entender o fenômeno da mudança de tamanho das estrelas. Nessa situação, a novidade da descoberta gerava a ansiedade por uma boa explicação. Os grupos ficavam sujeitos a uma suposição básica de acasalamento todas as vezes que precisavam apenas observar ou descrever a mudança de tamanho das estrelas. Eles procuravam interpretar o fenômeno na esperança que isso os levasse a uma boa descrição da observação. Quando isso não acontecia, refletiam sobre suas ações e procuravam redirecionar o trabalho para alcançar os objetivos estabelecidos em plenária. Aos poucos, os grupos passaram a acompanhar e testar as informações fornecidas pelos colegas nas discussões coletivas.

Os momentos em que atuaram como Grupos de Trabalho, de maneira cooperativa em torno da tarefa de aprendizagem, ocorreram em dimensões diferentes para cada um dos grupos. Em geral, os grupos conduziram essa tarefa com autonomia e, ao participar da discussão coletiva, sentiram a necessidade de ter seus pressupostos, observações ou interpretações validados perante os outros grupos. Nesse contexto, percebemos que a intervenção do professor foi fundamental para aproximar os alunos dos objetivos das tarefas de aprendizagem. Tanto a explicitação dos objetivos, quanto o engajamento dos alunos se consolidaram ao longo da atividade devido às intervenções do professor.

\section{CONCLUSÕES E IMPLICAÇÕES}

Os resultados evidenciam o potencial dos conceitos psicanalíticos de Bion ( 196 I) na análise da dinâmica de grupos de aprendizagem em atividades de laboratório escolar. Esses conceitos permitiram identificar as condições nas quais pequenos grupos se envolveram em trabalho colaborativo em torno de 
uma tarefa de aprendizagem. A ideia de Grupo de Trabalho e as diferentes modalidades de Suposição Básica propiciaram um mapa das interações dentro dos grupos, juntamente com uma inspiração teórica sobre as razões para isso ocorrer. A dificuldade de descrever o que os slides mostravam, por exemplo, preocupava os alunos. Eles, no caso, apresentaram explicações familiares que aliviaram a tensão com a tarefa de aprendizagem. As discussões em plenária evidenciaram que aquela dificuldade era comum e ajudaram a redirecionar o trabalho dos grupos para a tarefa de observação e descrição.

Tudo isso nos credencia a reivindicar que o professor não negue sua autoridade. É o professor que saberá como conduzir à tarefa de aprendizagem claramente e quando retomá-la, se necessário. De acordo com os resultados, os grupos não trabalham de maneira colaborativa em torno da tarefa de aprendizagem quando: eles não a entendem; ela é vaga ou difícil demais; o professor toma decisões pelo grupo; os impulsos emocionais que afastam os alunos da tarefa não são postos na perspectiva de coisas naturais que impedem o progresso; nada é feito a respeito. No estudo, os alunos voltaram a ser colaborativos e a agir como Grupo de Trabalho em torno das tarefas de aprendizagem à medida que a dinâmica estabelecida pelo professor permitiu isso. Em síntese, um equilíbrio entre autonomia dos pequenos grupos e liderança externa é essencial. Esses resultados corroboram outros que obtivemos em trabalhos anteriores.

\section{REFERÊNCIAS BIBLIOGRÁFICAS}

ADEY, P. et al. Depends on the context, doesnt it? Searching for general, educable dragons. Studies in Science Education, Leeds, v. 29, p.45-92, 1997.

BAROLLI, E.; BARROS, M. A; VILLANI, A. A Evolução de um grupo de aprendizagem num curso de física de ensino médio. Revista Brasileira de Pesquisa em Educação em Ciências, Porto Alegre, v. I, n.2, p.6-18, 2001.

BAROLLI, E.; VILLANI, A. Subjetividade e laboratório didático. Investigações em Ensino de Ciências, Porto Alegre, v.3, n.3, p. I43-159, 1998.

. Trabalho em grupos no laboratório didático: reflexões a partir de um referencial psicanalítico. Ciência \& Ensino, Unicamp, n.6, v. I I, 2003.

BARRON, B. When smart groups fail. Journal of the Learning Sciences, London, n. I2, p.30759, 2003. 
BARROS, M. A.; LABURU, C. E.; ROCHA, Z. Análise do vínculo entre grupo e professora numa aula de ciências do ensino fundamental. Ciência \& Educação, Bauru, v. I3, n.2, p.23525 I, 2007.

BARROS, M. A.; VILLANI, A. A Dinâmica de grupos de aprendizagem de física no ensino médio: um enfoque psicanalítico. Investigações em Ensino de Ciências, Porto Alegre, v.9, n.2, p. I-24, 2004.

BION, W. R. Experiences in groups. London: Tavistock, I96I.

BORGES, A. T.; BORGES, O. N.; Inovar - currículos: desenvolvendo o pensar e o pensamento científicos, jul. 200I. (Projeto integrado de pesquisas apresentado ao CNPq)

BORGES, A. T.; GOMES, A. D. Percepção de estudantes sobre desenhos de testes experimentais. Caderno Brasileiro de Ensino de Física, Florianópolis, v. 22, n, I , p.7I-94, abr. 2005.

BORGES, A. T.; VAZ, A. BORGES, O. Students: reasoning in the Physics laboratory. In: INTERNATIONAL CONFERENCE OF THE EUROPEAN SCIENCE EDUCATION Research Association, 3, 200 I, Thessalonik. Anais... Thessalonik: Aristotle University, 200 I . v.2, p.313-3|5.

COLEMAN, E. Using explanatory knowledge during collaborative problem solving in science. The Journal of the Learning Sciences, London, v.7, p.387-427, 1998.

DUSCHL, R. A.; OSBORNE, J. Supporting and promoting argumentation discourse in Science Education. Studies in Science Education, Leeds, n.38, p.39-72, 2002.

HOGAN, K.; NASTASI, B. K.; PRESSLEY, M. Discourse patterns and collaborative scientific reasoning in peer and teacher-guided discussions. Cognition and Instruction, Philadelphia, n. 17, p.379-432, 2000.

JÚLIO, J. M.; VAZ, A. M. Grupos de Alunos como grupos de trabalho: análise e avaliação de atividades de investigação escolar em física. In: ENCONTRO DE PESQUISA EM ENSINO DE FÍSICA, 9, 2004, Jaboticabas. Atas... Jaboticabas: SBF, 2004. (CD-ROM)

O Professor de física como "co-pensor" em "grupos operativos" de alunos do ensino médio. In: ENCONTRO DE PESQUISAS EM EDUCAÇÃO EM CIÊNCIAS, 5, 2005, Bauru. Anais... Bauru: Associação Brasileira de Ensino em Ciências, 2005.

JÚLIO, J. M.; VAZ, A. M.; FAGUNDES, A. F. Atenção - alunos engajados: análise de investigação escolar em grupo. In: ENCONTRO DE PESQUISA EM ENSINO DE FÍSICA, I0, 2006, Londrina. Comunicação oral... Londrina: SBF, 2006.

MILLAR, R. A Means to an end: the role of processes in science education. In: WOOLNOUGH, B. (Ed.). Practical science. Buckingham: Open University, 1991. Cap.5, p.43-52. 
SHOR, I.; FREIRE, P. A Pedagogy for liberation: dialogues on transforming education. New York: Bergin \& Garvey, 1987.

VAZ, A. Being challenged: reflections on the contribution of Paulo Freire's work to teacher education: the thematic investigation of primary teachers thinking and practice with regard to the teaching of science. 1996. PhD (Thesis) - Centre for Learning and Research in Science Education, Roehampton Institute, University of Surrey, Surrey.

Recebido em: novembro 2007

Aprovado para publicação em: dezembro 2008 